\title{
Assessment of Suicidal Behavior in a Psychiatric Emergency Room in Lisbon, Portugal
}

\author{
Avaliação do Comportamento Suicida numa Urgência Psiquiátrica em Lisboa, \\ Portugal
}

João GAMA MARQUES $\square^{1,2}$, Diogo FRASQUILHO GUERREIRO¹, Daniel SAMPAIO ${ }^{1}$

Acta Med Port 2015 Jul-Aug;28(4):469-473

\section{ABSTRACT}

Introduction: Some studies alerted for the burden of suicidal attempters at emergency rooms. In this study we characterized the suicidal patients admitted to a Portuguese emergency room.

Material and Methods: For three years, all patients assessed by the first author after suicidal behaviour were included. Suicidal intentionality was evaluated with the Pierce Suicide Intent Scale. Clinical records were searched for follow-up status and satisfaction level was assessed through telephone call.

Results: From 120 included patients $70.8 \%$ were female, with mean age of 42.35 years. Pierce Suicide Intent Scale suicidal intentionality was low in $30.1 \%$, medium in $59.3 \%$, and high in $10.6 \%$ of the sample. The most important predictors of Pierce Suicide Intent Scale intentionality were male gender $(p<0.001)$, family history of suicide $(p<0.01)$, divorced or widowed marital status $(p<0.013)$, and severe mental illness $(p<0.015)$. In $41.6 \%$ of the patients the follow-up status was unknown. Regarding satisfaction, only $19.5 \%$ gave a valid answer: $2.7 \%$ 'mildly satisfied', $4.4 \%$ 'moderately satisfied', and $12.5 \%$ 'very satisfied'.

Discussion: The Pierce Suicide Intent Scale is useful on suicidal behavior assessment at emergency rooms. Highly intentional suicidal behaviour is related to male sex, social problems and personal and familial psychiatric history.

Conclusion: The quality of administrative records on this psychiatric emergency room setting are still unacceptable. The most important variables correlated with higher suicidal intentionality are the same described in other countries. Of the reachable patients, one fifth was satisfied with provided follow-up. We still need studies for better understanding of suicidal behaviour observed on this Portuguese emergency room.

Keywords: Emergency Service, Hospital; Intention; Portugal; Questionnaires; Self-Injurious Behavior; Suicide, Attempted.

\section{RESUMO}

Introdução: Alguns estudos têm alertado para a sobrecarga de tentativas de suicídio nas urgências médicas. Neste estudo caracterizamos os doentes suicidas numa urgência médica portuguesa.

Material e Métodos: Durante três anos, todos os doentes observados pelo primeiro autor, em urgências médicas, após tentativa suicida, foram incluídos no estudo. A intencionalidade da tentativa suicida foi determinada com a Pierce Suicide Intent Scale. O seguimento foi registado recorrendo ao processo clínico, e o nível de satisfação a chamada telefónica.

Resultados: Dos 120 doentes incluídos 70,8\% eram mulheres e a média de idades foi 42,35 anos. A intencionalidade suicida (Pierce Suicide Intent Scale) foi baixa em 30,1\%, média em 59,3\% e elevada em 10,6\%. Os principais preditores de intencionalidade suicida foram: género masculino $(p<0,001)$, história familiar de suicídio $(p<0,01)$, divórcio ou viuvez $(p<0,013)$ e doença mental grave $(p<0,015)$. Em $41,6 \%$ dos doentes não se apurou seguimento. Quanto à satisfação, apenas $19,5 \%$ deram resposta válida: $2,7 \%$ "ligeiramente satisfeito", 4,4\% "moderadamente satisfeito", e 12,5\% "muito satisfeito".

Discussão: A Pierce Suicide Intent Scale é um instrumento útil na avaliação do comportamento suicida na urgência médica. 0 comportamento suicida de elevada intencionalidade está relacionado com género masculino, problemas sociais e antecedentes psiquiátricos pessoais e familiares.

Conclusão: Os registos administrativos da urgência médica são ainda pouco rigorosos. As variáveis relacionadas com intencionalidade suicida são as mesmas que são descritas noutros países. Dos doentes a que conseguimos chegar, um quinto mostrou-se satisfeito com o seguimento. Mais estudos são necessários para compreender o comportamento suicida em Portugal.

Palavras-chave: Comportamento Autodestrutivo; Intenção; Portugal; Questionários; Serviço de Urgência Hospitalar; Tentativa de Suicidio.

\section{INTRODUCTION}

The word suicide derives from the latin term sui caedere, meaning 'to kill oneself'. However, the definition of suicide is inherently more complex than the simple words 'killing oneself'. ${ }^{1}$ Presently, the area of suicidology nomenclature is troubled with various definitions that have unclear limits and overlaps, leading to marked implications for understanding prevalence rates, gender differences, risk factors and motivations for suicidal behaviour. ${ }^{2}$

In this work we use some terminology outlined in recent consensus: 'suicide' as the act of intentionally ending one's own life and 'suicidal behaviors' which refers to engagement in potentially self-injurious behavior in which there is at least some intent to die. ${ }^{3}$ Thus suicidal behaviors include, in our view, different concepts as suicide attempt, self-mutilation, deliberate self harm and parassuicide.

Although the concept of suicide can be discussed in

1. Clínica Universitária de Psiquiatria e Psicologia Médica. Faculdade de Medicina. Universidade de Lisboa. Lisboa. Portugal.

2. Clínica de Psicoses Esquizofrénicas. Hospital Júlio de Matos. Centro Hospitalar Psiquiátrico de Lisboa. Lisboa. Portugal.

$\square$ Autor correspondente: João Gama Marques. joaogamamarques@gmail.com

Recebido: 09 de Outubro de 2014 - Aceite: 19 de Junho de 2015 | Copyright @ Ordem dos Médicos 2015 
several points of view, medical, philosophical, sociological or even politically, leading to interesting theories, no one can deny suicide is a serious and global public health concern. ${ }^{4}$ Suicide causes almost one million of deaths every year worldwide, and global suicide rate was estimated as 11.6 per 100000 inhabitants in $2008 .{ }^{5}$ According to World Health Organization data, Portugal's suicide rate was estimated in 9.6 per 100000 for the year of $2009^{6}$ although some authors think that number is underestimated due to death's certificate recording errors and secondary statistical bias, ${ }^{7}$ a common issue that also happens in other parts of the world. ${ }^{8}$

Many factors have been related to the development and maintenance of suicidal behavior, such as genetics, childhood abuse, family hostility, poor distress tolerance, social problem-solving and communication skills, interacting with stress response and regulation of affective experience. ${ }^{9}$ Some functions have been proposed for this deliberate selfinjury (e.g., seeking help or expressing anger). ${ }^{10}$

Deliberate self harm has been described as a significant and persistent risk of suicide. ${ }^{11}$ Some studies have already alerted for the burden of suicidal attempters in other Europeans emergency rooms. ${ }^{12}$ Sometimes no one is able to fully understand what's happening, especially while on a psychiatric emergency room (ER) setting, where fast decisions are needed, and even copycat suicide behaviours can be presented. ${ }^{13}$ Although suicide after ER discharge is rare ${ }^{14}$ the assessment shall be accurate as possible as suicidal behaviour assessment is not an easy issue. ${ }^{15}$

With the present study we set out to perform a detailed characterization of patients who were admitted to an urban psychiatric emergency room, following suicidal behaviour. We focus searched several factors in order to verify which better predict suicide intention, allowing a more precise evaluation of risk. We also looked for satisfaction levels among patients treated in our ER department, after an episode of deliberate self-harm, parassuicide or suicide attempt.

Knowing these answers will help the authors to enhance practice in psychiatric ER setting, by increasing the quality of patient's care, and refereeing them to more adequate psychiatric structures.

\section{MATERIAL AND METHODS}

During a three year span, all patients admitted for suicidal behaviour, and assessed by the first author during his weekly shift at the ER in Hospital Curry Cabral (20102011) and Hospital São José (2012) in Lisbon, Portugal.

Demographic variables, familial, personal, psychiatric and past suicidal behaviour history were collected. Diagnosis was made using ICD-10 criteria after mental state observation and clinical records examination, if available.

Suicidal behaviour method was recorded in classical categories such as: jumping from high place; drowning; hanging; self-poisoning; medication overdose and selfcutting.

Suicidal intentionality was evaluated with Pierce
Suicide Intent Scale (PSIS), an instrument composed by 12 questions regarding three suicidal behaviour aspects: circumstances (e.g., where, when, search for help, suicide note); self-report (e.g., premeditation, regret); and risk (e.g., death's probability). PSIS result ranges from a minimum score of 0 to a maximum of 25 , categorizing the suicidal intent attempt in: low (0 - 3 points), medium (4 - 10 points) and high (11 - 25 points). ${ }^{16}$ PSIS was translated and adapted (but not validated) to Portuguese language and population by an active member of the Portuguese Society of Suicidology (António Fonte 2007, unpublished).

Whenever assessment didn't end in admittance to psychiatric ward, the patient was discharged with a written letter to keep follow-up in our psychiatric outpatient clinic services. For those patients living outside our catchment area, the destination was another hospital psychiatric ward or, in case of discharge, the psychiatric outpatient services of the residential area.

Regarding follow-up, a computer search was made on clinical records system. We looked for followup characteristics as type and duration of outpatient consultation, the respective ICD-10 diagnosis, and number of admittances in our psychiatric ward. On those living outside our catchment area, and were admitted in a psychiatric ward of another hospital, an e-mail was sent to colleagues asking for their clinical records. On those without any clinical records in our hospital, or discharged to a different outpatient services, a single telephone call was made to the patient trying to know if any follow-up existed outside our hospital services. A structured interview was made (nine months after, through three different times of the day phone call attempts) trying to know the characteristics of follow-up: type (public versus private services; general practitioner, psychologist or psychiatrist), the duration (in days), and the satisfaction (Likert-like scale from 1 to 5).

All data were transferred to SPSS version 20 and cleaned prior to analysis. General descriptive statistics were conducted to examine the sample in terms of demographic, clinical, management, follow-up and suicidal behaviour variables.

Study participants were then divided into three groups according to the suicidal intent categories of the PSIS: Iow intentionality, medium intentionality and high intentionality. The suicidal behaviour method variables were clustered in two groups according to the usual lethality associated with the same: self-cutting and overdose were considered low lethality methods, while the remainder (poisoning, asphyxia, jumping from high point) were considered as more lethal methods.

For statistical purposes, the ICD10 diagnosis were divided in two categories: severe mental illness (like depression, bipolar and schizophrenia related disorders) and less severe mental illness (substance abuse, anxiety related disorders and personality disorder). Chi-square test, adjusted residuals and estimated odds ratio, were used to assess the statistical significance of associations for categorical variables. Mann-Whitney $U$ and Kruskal- 
Wallis Tests were used for continuous variables. High suicide intentionality predictors were examined in logistic regression analyses. Alpha-level was set at $5 \%$.

\section{RESULTS}

From the 120 patients included seven records were lost, remaining 113. Most of patients were admitted on day shifts (54.9\%). Circa $76.1 \%$ of the patients were sent from other hospital services, $17.7 \%$ came from the community without referral and $6.2 \%$ were sent by primary care professionals (e.g. general practitioner).

The sample consisted of $70.8 \%$ female patients. The youngest patient had 17 and the oldest 90 years old, with a mean value of 42.35 years and a standard deviation (SD) of 17.3 year old. Regarding marital status $36.3 \%$ were single, $36.3 \%$ were married, $15.9 \%$ were divorced and $11.5 \%$ were widow. When asked with whom the patient lived, $21.2 \%$ were living alone, $31.9 \%$ with one more person, $19.5 \%$ with two more persons, $27.4 \%$ with three or more persons. In terms of occupation $55.8 \%$ were employed, and $27.4 \%$ unemployed and $16.8 \%$ retired.

Destination of patients was unknown in $1.8 \%$ (e.g., abandoned ER without clinical observation); $61.9 \%$ were discharged with referral letter to their outpatient psychiatric services or general practitioner; $26.5 \%$ were admitted on our psychiatric wards; and $9.7 \%$ were transferred to another hospital.

Regarding follow-up: In $41.6 \%$ was impossible to find if there was any kind of follow-up; $24.8 \%$ kept the followup in psychiatry; $15.9 \%$ kept the follow-up in psychiatry and psychology consultations and $8 \%$ got discharged from psychiatrist and kept follow-up on general practitioner. The mean duration of follow-up was 163.4 days (almost 23 weeks) with a standard deviation of 240.0 days.

The frequency of ICD-10 major diagnosis categories were: $14.2 \%$, substance related disorders (F10 - 19); 4.4\% psychotic and related disorders (F20 - 29); 10.6\% bipolar disorders (F30 - 31); 47.8\% depressive disorders (F32 39); $15 \%$ anxiety disorders (F40 - 49 ); and $8 \%$ personality disorders (F60 - F69). The consistence of the diagnosis was confirmed in $38.8 \%$ of the patients, on posterior clinical recordings in our and other hospitals.

The most used methods of suicidal behaviour were: $66.4 \%$ overdose; $17.7 \%$ self-cutting; $8 \%$ asphyxia; $5.3 \%$ poisoning; $2.7 \%$ and jumping from high point.

Intentionality assessed through PSIS results had a minimum value of 0 and a maximum value of 18 , with a mean value of 5.63 and a SD of 2.5. The proportions of the three PSIS suicidal intentionality categories were: $30.1 \%$ low; $59.3 \%$ medium and $10.6 \%$ high.

We found no significant differences (both in sample characteristics or results) in the distribution among the years of the study (2010, 2011 and 2012).

Using the PSIS total score as measure, we observed that intentionality was higher in males (Mann-Whitney $U$ Test; $p=0.05$ ); widows, divorced (Kruskal-Wallis Test; $p=$ 0.01 ) and retired patients (Kruskal-Wallis Test; $p=0.001$ ).
Besides that suicidal behaviour intentionality was also higher in patients with family suicide history (Mann-Whitney U Test; $p=0.02$ ).

When comparing the two groups based on low or high lethality method, we observed a non statistically significant tendency in which the low lethality group (overdoses and self-cutting) showed lesser total scores on the intentionality scale. After a categorization grouping of ICD10 diagnosis a higher intentionality was found among severe mental illness (like depression, bipolar and schizophrenia related disorders) versus other mental disorders.

In a linear regression stepwise model $(R=0,6)$ the most important predictors of high intentionality according to the PSIS (with higher odds ratio) were male gender $(B=2.33$, $p<0.001)$, family history of suicide $(B=1.66, p<0.010)$, divorced or widowed marital status $(B=1.78, p<0.013)$ and severe mental illness $(B=1.43, p<0.015)$.

When looking at the data with the second measure of intentionality by categories (e.g., low, medium and high intentionality) there were some statistically significant associations. High intentionality was associated with widowed marital status ( $p=0.001)$; retired occupation ( $p$ $=0.007)$; living alone $(p<0.001)$. In the other hand low intentionality was associated with less severe mental illness $(p=0.005)$.

In $66.1 \%$ of patients it was impossible to find if there was a new suicidal behaviour: $36.1 \%$ didn't answer the phone call and $30 \%$ had no correct telephone contact at all on the clinical file. The remaining $33.9 \%$ showed no more suicidal behaviour on $28.5 \%$ (including two patients who died with a neoplasm), and only $5.3 \%$ tried new suicidal behaviour (with no known death on this group). Almost one fourth (24.8\%) of the patients returned to the psychiatric ER, with a mean value of 0.76 returns and a standard deviation of 1.739 , meaning that not all suicidal behaviour repeaters searched for ER services on a second episode. On the telephone call structured interview only $19,5 \%$ of the sample gave a valid answer. Of those there were no 'no satisfied' and no 'poorly satisfied' results ( 1 or 2 on a Likert-like 1 to 5 rating scale). Thus $2.7 \%$ got 'mildly satisfied', $4.4 \%$ got 'moderately satisfied' and $12.5 \%$ got 'very satisfied' with their follow-up after the suicidal behaviour detected in the ER.

\section{DISCUSSION}

During this work we felt many difficulties accessing the clinical files and a great percentage of those had incorrect contact details, which lowered considerably the response rate of our telephone follow-up satisfaction survey.

Our sample was quite small when compared with studies from other countries using similar assessment tools. ${ }^{17}$ Like other authors suggested already before, we felt that these kind of scales can be useful in the assessment of suicidal behavior in the ER. ${ }^{18}$ This is important to identify patients at the lowest suicide risk in the $\mathrm{ER}^{19}$ that may later adopt methods with higher case-fatality ratios. ${ }^{20}$

In the other hand our results were compatible with those published by other authors: suicidal behaviour seems to 
be related to male sex, widowed or divorced status and social isolation, ${ }^{21}$ unemployment, ${ }^{22}$ personal history of major depression ${ }^{23}$ and family history of suicide. ${ }^{24}$ Thus suicide prevention should be planned and executed in four different levels: primordial (e.g., social interventions against unemployment), primary (e.g., limitations to access lethal methods), secondary (e.g., psychological and pharmacological intervention to avoid repetition of suicidal behavior); and tertiary (e.g., familiar intervention on siblings of victims of completed suicide). This kind of interventions is essential, and should be applied especially in the patients with previous suicide behavior, for better and more effective suicide prevention.

The main limitations of our study were the small size of sample; the usage of a non validated instrument for the Portuguese population; the bias of a unique clinician as observer, without structured diagnosis assessment; and the high percentage of patients lost at follow-up searching (66.1\%).

Some recent works found different prevalence on suicidal behavior among immigrant community members, ${ }^{25}$ especially when presented with feelings of hopelessness. ${ }^{26}$ That could be a potential focus of interest in future studies in Portugal. Other interesting aspect to study would be the full pathway of patients through the health system, ${ }^{27}$ from primary care to the emergency room, and then after discharge, when returning to their community.

\section{CONCLUSION}

The authors concluded that administrative records on this Portuguese psychiatric ER setting failed much more than expected (and acceptable) with more than one third $(36 \%)$ of lost telephone contact numbers. This issue decreased a lot the response rate of the satisfaction survey, but also impaired the localization of many virtual survivors.
It also impaired the author's capability to track down many patients and the respective prognosis (e.g. repetition of self harm behaviour, death or clinical remission).

As have been published before for a long time by many authors, the most important variables correlated with a higher suicidal behaviour intentionality were the male gender, widow or divorced marital status, professionally retired, and suicide history in the family. Thus more efforts should be done trying to help this at risk sub-populations on the primary care and psychiatric services already provided.

Although the authors found that, at least, one fifth of the sample were satisfied with the follow-up provided, there is still an urge need for bigger studies for a better understanding of what happens to patients with suicidal behaviour that are observed on the psychiatric ER in Portugal, after discharge.

Last but not least, more and stronger studies are needed for a better understanding of suicidality in our country, especially in these times of austerity we are living on. ${ }^{28,29}$

\section{PEOPLE AND ANIMALS PROTECTION}

The authors declare that the procedures were followed according to the regulations established by the Clinical Research and Ethics Committee and to the Helsinki Declaration of the World Medical Association.

\section{CONFIDENTIALITY OF DATA}

The authors declare having followed the protocols in use at their working center regarding patient's data publication.

\section{CONFLICTS OF INTEREST}

The authors declare that there are no conflicts of interest.

\section{FUNDING SOURCES}

No subsidies or grants contributed to this work.

\section{REFERENCES}

1. De Leo D, Burgis S, Bertolote JM, Kerkhof AJ, Bille-Brahe U. Definitions of suicidal behaviour: lessons learned from the WHo/EURO multicentre Study. Crisis. 2006;27:4-15.

2. Silverman MM, Berman AL, Sanddal ND, O'Carroll PW, Joiner TE. Rebuilding the tower of Babel: a revised nomenclature for the study of suicide and suicidal behaviours. Part 1: Background, rationale, and methodology. Suicide Life Threat Behav. 2007;37:248-63.

3. Nock MK, Borges G, Bromet EJ, Cha CB, Kessler RC, Lee S. Suicide and suicidal behaviour. Epidemiol Rev. 2008;30:133-54.

4. Khan MM, Mian Al. 'The one truly serious philosophical problem' ethical aspects of suicide. Int Rev Psychiatry. 2010;22:288-93.

5. Värnik P. Suicide in the world. Int J Environ Res Public Health. 2012;9:760-71.

6. World Health Organization. Suicide rates (per 100,000), by gender Portugal [accessed 2014 Oct 6]. Available at: http://www.who.int/ mental health/media/port.pdf.

7. Saraiva CB. Suicídio, de Durkheim a Schneidman, do determinismo social à dor psicológica individual. Psiquiatria Clín. 2010;31:285-305.

8. Bertolote JM, De Leo D. Global suicide mortality rates - a light at the end of the tunnel? Crisis. 2012;33:249-53.

9. Nock MK. Why do people hurt themselves? New insights into the nature and functions of self-injury. Curr Dir Psychol Sci. 2009;18:78-83.

10. Klonsky ED. The functions of deliberate self-injury: a review of the evidence. Clin Psychol Rev. 2007;27:226-39.

11. Hawton K, Zahl D, Weatherall R. Suicide following deliberate self-harm:

long-term follow-up of patients who presented to a general hospital. $\mathrm{Br}$ J Psychiatry. 2003;182:537-42.

12. Schmoll S, Boyer L, Henry JM, Belzeaux R. Frequent visitors to psychiatric emergency service: Demographical and clinical analysis. Encephale. 2015;41:123-9.

13. Kim WJ, Song YJ, Namkoong K, Kim JM, Yoon HJ, Lee E. Does a copycat effect exist in the emergency department? Int J Psychiatry Med. 2013;45:59-72.

14. Rafnsson V, Gunnarsdottir OS. All-cause mortality and suicide within 8 days after emergency department discharge. Scand J Public Health. 2013;41:832-8.

15. Bethel J. Assessment of suicidal intent in emergency care. Nurs Stand 2013;28:52-8.

16. Pierce DW. Suicidal intent in self-injury. Br J Psychiatry. 1977;130:37785.

17. Sisask M, Kõlves K, Värnik A. Severity of attempted suicide as measured by the Pierce Suicidal Intent Scale. Crisis. 2009;30:136-43.

18. Waern M, Sjo N, Marlow T, Hetta J. Does the Suicide Assessment Scale predict risk of repetition? A prospective study of suicide attempters at a hospital emergency department. Eur Psychiatry. 2010;25:421-6.

19. Ronquillo L, Minassian A, Vilke GM, Wilson MP. Literature-based recommendations for suicide assessment in the emergency department: a review. J Emerg Med. 2012;43:836-42.

20. Miller M, Hempstead K, Nguyen T, Barber C, Rosenberg-Wohl S, Azrael D. Method choice in nonfatal self-harm as a predictor of subsequent 
episodes of self-harm and suicide: implications for clinical practice. Am J Public Health. 2013;103:e61-8.

21. Kapur N, Gask L. Introduction to suicide and self-harm. Psychiatry. 2006;5:259-62

22. Milner $A$, Page $A$, LaMontagne $A D$. Long-term unemployment and suicide: a systematic review and meta-analysis. PLoS One. 2013;8:e51333

23. Bolton JM, Robinson J. Population-attributable fractions of axis I and axis II mental disorders for suicide attempts: findings from a representative sample of the adult, non institutionalized US population. Am J Public Health. 2010;100:2473-80.

24. Ganz D, Braquehais MD, Sher L. Secondary prevention of suicide PLoS Med. 2010;7:e1000271.
25. Zeppegno P, Gramaglia C, Castello LM, Bert F, Gualano MR, Ressico $F$, et al. Suicide attempts and emergency room psychiatric consultation. BMC Psychiatry. 2015;15:13.

26. Menon V, Kattimani S, Shrivastava MK, Thazath HK. Clinical and socio-demographic correlates of suicidal intent among young adults: a study from South India. Crisis. 2013;34:282-8.

27. Ramos J, Santos J, Jorge S, Maia T, Cardoso G. Pathways to care for first psychiatric admissions in Lisbon. Psychiatr Serv. 2015;66:888-91.

28. Augusto GF. Mental health in Portugal in times of austerity. Lancet Psychiatry. 2014;1:109-10.

29. Gama Marques J, Brissos S. Mental health in Portugal in times of austerity. Lancet Psychiatry. 2014;1:260. 


\section{Assessment of Suicidal Behavior in a Psychiatric Emergency Room in Lisbon, Portugal}

Acta Med Port 2015:28:469-473

Publicado pela Acta Médica Portuguesa, a Revista Científica da Ordem dos Médicos

Av. Almirante Gago Coutinho, 151

1749-084 Lisboa, Portugal.

Tel: +351218428215

E-mail: submissao@actamedicaportuguesa.com

www.actamedicaportuguesa.com

ISSN:0870-399X | e-ISSN: 1646-0758

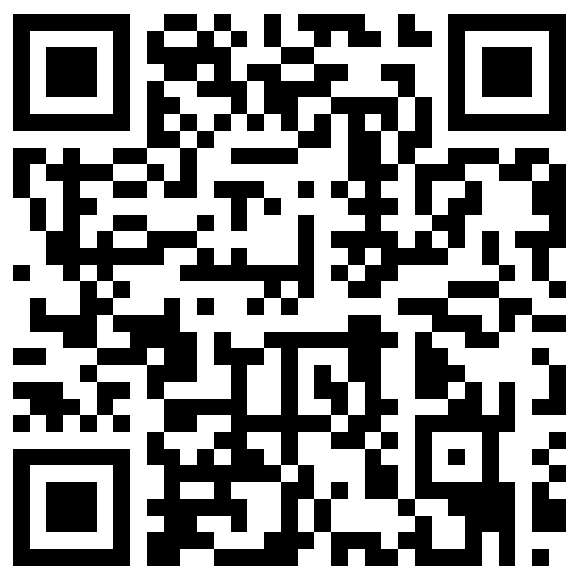

